The BDJ News section accepts items that include general news, latest research and diary events that interest our readers. Press releases or articles may be edited, and should include a colour photograph if possible. Please direct your correspondence to the News Editor, Arveen Bajaj at the BDJ, 64 Wimpole Street WIG 8YS or by email to bdj@bda.org

\section{Newly appointed}

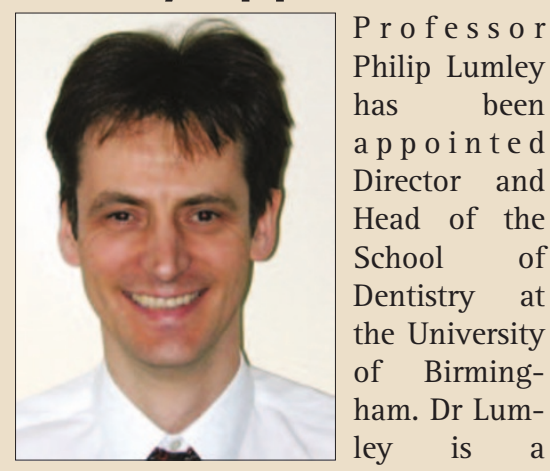

Professor of Endodontology, and qualified in Dundee in 1980. He was appointed lecturer in Conservative Dentistry following house officer and registrar jobs in Dundee and Glasgow.

He gained his Master of Dental Science, $\mathrm{PhD}$ and Certificate of Accreditation in Restorative Dentistry at Birmingham, he also holds fellowships of the Glasgow, London and Edinburgh colleges. He has researched extensively in the field of endodontology and clinical interests include the use of the operating microscope especially in root canal re-treatment.

\section{Award winner}

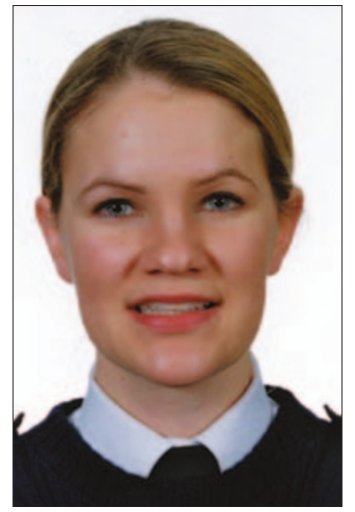

Surgeon Lieutenant Laura Stevenson, a Royal Navy dental officer working with the Defence Dental Agency, has been awarded this year's GDC

Charitable Trust Prize for Professionalism. The award acknowledged her patient care, clinical governance, team working, communication skills, integrity and knowledge of professional responsibilities.

\section{Youngsters have top teeth}

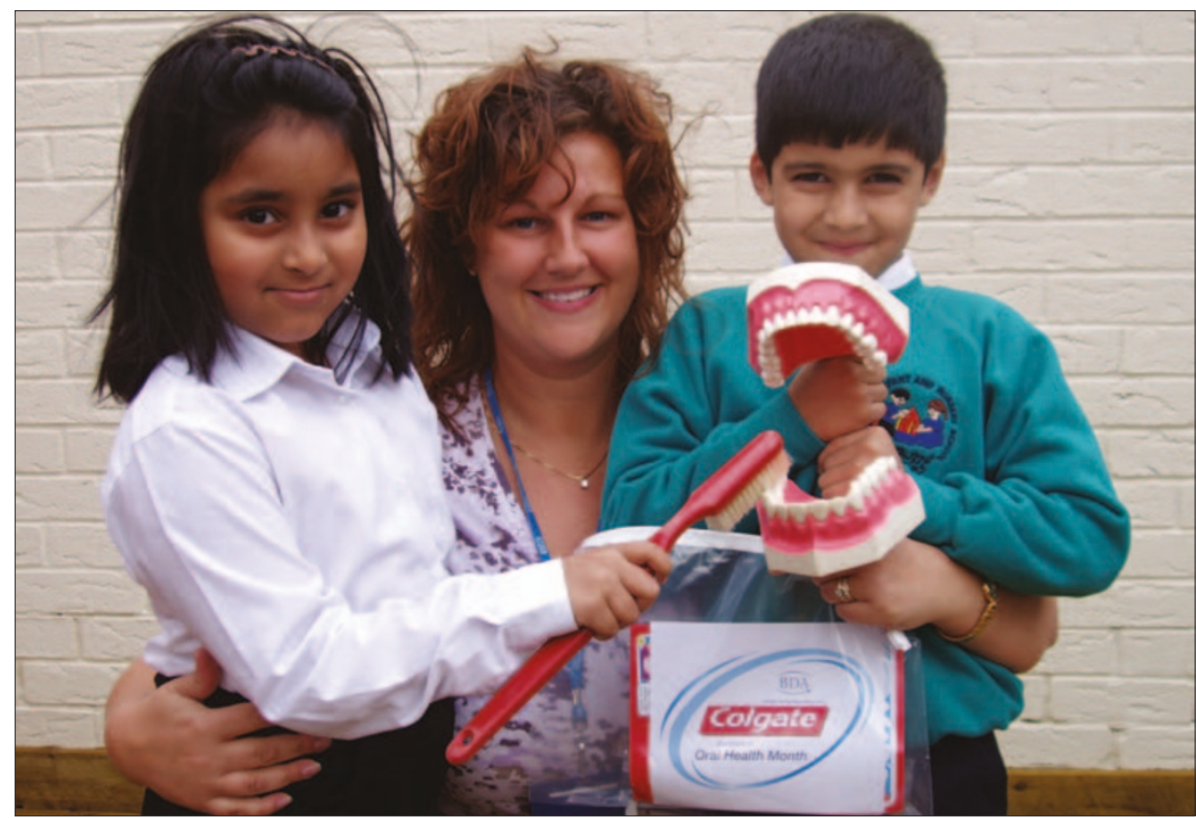

For the first time in $\mathbf{2 0}$ years of measuring decay more than half the five-year-olds in the borough of Oldham have no tooth decay at all. Oldham's Community Dental Service promotes oral health, particularly in families and children, by working within schools and communities and with organisations such as Sure Start, as well as with GPs, pharmacists, health visitors and other health professionals. They also provide dental treatment for priority groups and people with special needs who would find it difficult to use other dental practices for various reasons. Pictured above: senior oral health promoter Sharon Hall with Glodwick school pupils Mariya Tabassum(left) and Umar Farooq (right).

\section{New foundation launched}

The Mouth Cancer Foundation recently celebrated its launch at the London Dental Showcase.

The Foundation was established in June this year to provide support for mouth, throat and other head and neck cancer patients and to increase mouth cancer awareness amongst the public.

Its aims are to co-ordinate and lead a mouth cancer awareness programme in the UK, to provide support for patients, carers and health professionals by providing a telephone helpline, an online support group and by providing a national co-ordination and support for local support groups.

It also aims to foster and undertake research into any aspect of the objects of the Foundation and its work and to disseminate the results of any such research

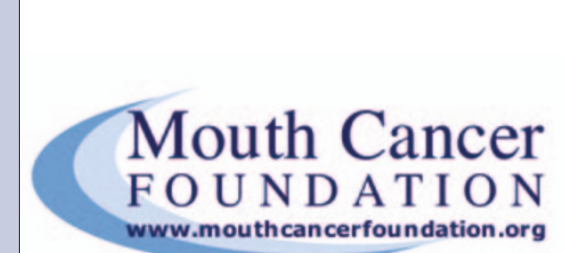

and to co-operate and enter into arrangements with any relevant authorities, national, local or otherwise.

Founder, Dr Vinod K Joshi intends to develop the existing website to become a definitive online resource and support group which has nearly 400 forum members.

For more information visit www.mouthcancerfoundation.org 


\section{DIARY}

November 2004

Building Effective Practice: Health Improvement in the Health Services Date: 03.11.04

Venue: Edinburgh

Contact: Health Service Programme at Health Scotland

Tel: +44 (0) 1315365500

Email: margaret.richardson@health. scot.nhs.uk

January 2005

OSAP 4th Annual Intermediate-Level Infection Control and Occupational Safety and Health Course

Date: 24-27.01.04

Venue: Hyatt Regency Atlanta, Georgia

Tel: 800-298-OSAP (6727)

www.osap.org.

International Dental Foundation 54th International Alpine Dental Conference

Date: 29.01.05-05.02.05

Venue: Hotel Annapurna, Courcheval 1850, France

Contact: Robert Wallace

Tel: +44 (0) 2072350788

Fax: +44 (0) 2072350767

Email: idf@idfdentalconference.com www.idfdentalconference.com

March 2005

83rd General Session \&t Exhibition of the IADR, 34th Annual Meeting of the AADR, 29th Annual Meeting of the CADR

Date: 9-12.03.05

Venue: Baltimore Convention Centre www.dentalresearch.org

\section{Blood tests halted}

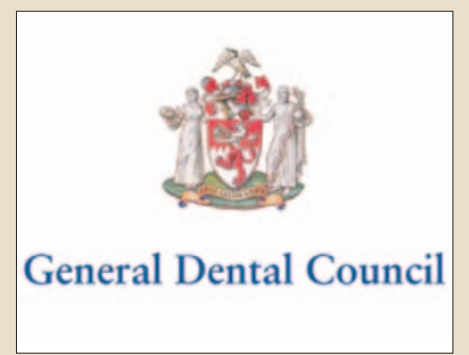

The GDC has decided to suspend its requirement for new registrants and those restoring their names to the Dentists Register, to have an HIV and Hepatitis C test. The requirement, which was introduced in February 2004, was suspended following concerns raised by final year dental students, deans of dental schools, GPs and the British Dental Association.

Some of the main concerns were that the tests were putting final students under great pressure in the run up to their exams, it was difficult for campus health services to arrange large numbers of tests, it was unclear who would provide counselling for HIV testing, many students had to pay for the tests which was difficult on limited income and that there were doubts about the scientific justification for HIV and hepatitis $\mathrm{C}$ testing.

Experts are set to advise the GDC on the latest scientific thinking around testing for HIV, hepatitis and TB. Once this advice is received, the Council will review its healthscreening and counselling policy.

In the meantime it states that applicants for GDC registration must still provide evidence that they are clear of TB and hepatitis B as there is a consensus that these conditions should be tested for, given the risk of transmission through dentistry.

\section{Charity opens clinic in Tanzania}

Charity Bridge2Aid has recently opened a new not for profit clinic, Hope Dental Centre in Mwanza, Tanzania.

The clinic is located in the centre and will, after the initial set up costs, be selffunding. All profits will reinvested to fund the charity's dental and social programmes and will treat those who can afford dental care while offering subsidised treatment for those who cannot.

In addition to this, the clinic will be used as a training centre for one day each fortnight in order that local dentists can be trained to offer the same high standard of dental care available at Hope Dental Centre. Bridge2Aid is a provider of primary dental care, oral health education and social care in Tanzania. Once a month Bridge2Aid travels out of Mwanza Town to take dental services to the rural areas.

These services, known as 'tooth camps' have become well known and according to the charity, people travel from far and wide to take advantage of the much-needed relief from dental problems.

During the tooth camps to areas where nearly $80 \%$ of the population of Mwanza live, in the past 12 months it has provided both free and subsidised dental care to approximately 700 people. At each fourhour camp the dentists see between 50 and 60 people and no charges are made for these services. For more information visit www.bridge2aid.org. 


\section{New degree available online}

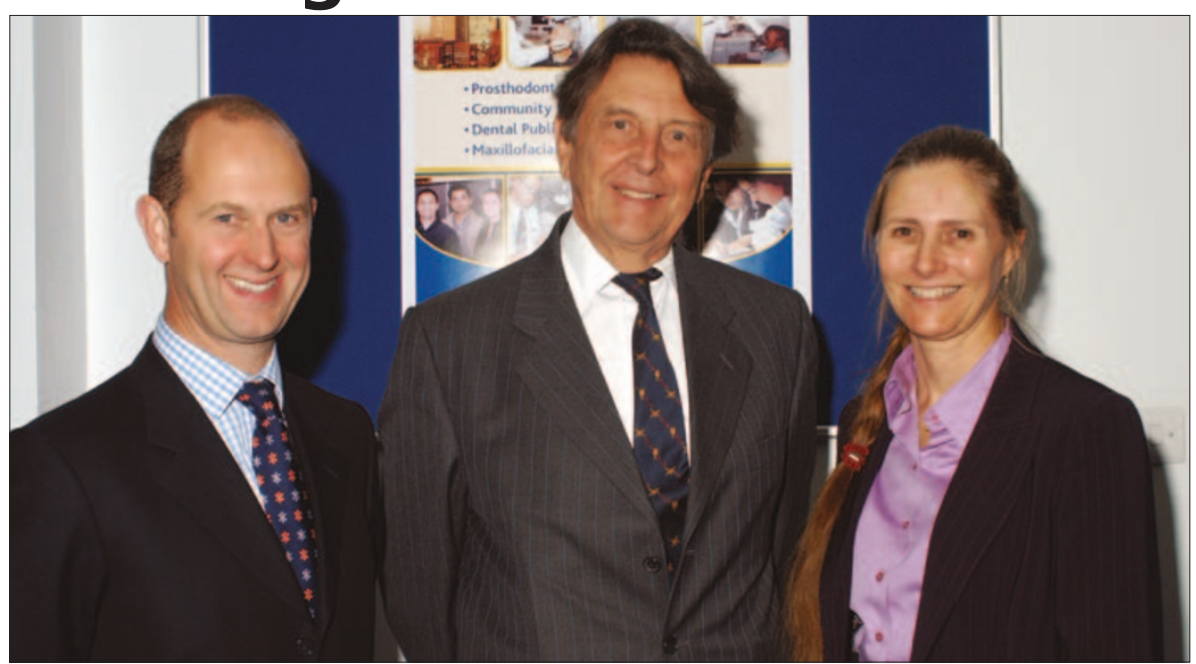

The first online postgraduate dental degree from King's College, the e-MClinDent (Prosthodontics) was officially launched at the 175th Anniversary Celebrations of King's College London in the Dental Institute recently. The course has been running since January 2004 with some 30 students worldwide and was planned, designed and orchestrated by the retiring programme director Professor David Smith in conjunction with the External Programme of London University. The students study their course through internet access and follow nine modules of eight units over a four year course. However, the students are not entirely remote, as there are short intensive residential courses each year when the students come to London for two weeks. According to the institution, the course was set up in answer for the need to be able to provide flexible study for busy globally based practitioners. (Pictured I-r, programme director Brian Millar, David Smith and Patricia Reynolds, Deputy Director of Education for Distance Learning.)

\section{Collaborative status achieved}

The Unit of Dental and Oral Health and Health Psychology at the University of Dundee Dental School has been designated a WHO Collaborating Centre for Public Health Issues on Congenital Anomalies and Technology Transfer. Professor Peter Mossey has been appointed Head of the Centre. Other members of the team that have achieved this collaborative status are Professor Bill Saunders, Dean of Dentistry, Professor David Stirrups, Professor of Orthodontics, Mr John Clark, Consultant in Orthodontics, Ms Pam Houston,
Research Assistant, and two new members, Dr Grant McIntyre Consultant in Orthodontics and Ms Janet Davies, Research Statistician, have recently joined the team at the Unit of Dental and Oral Health and Health Psychology, Dundee Dental Hospital.

In addition there are two external collaborators, Dr David Fitzpatrick, Senior Research Scientist at the MRC Human Genetics Unit in Edinburgh and Professor Julian Little, Professor of Epidemiology, University of Aberdeen.

\section{Practice recognised as liP}

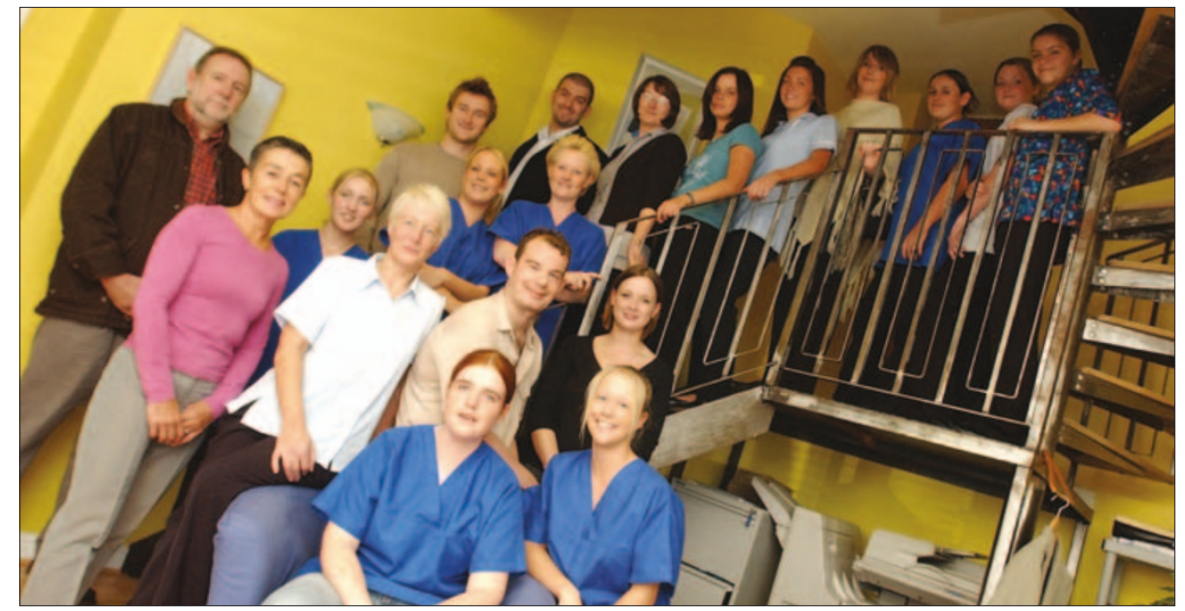

A dental practice in South Shields has been recognised as an Investor in People. 1A The Dental Practice has been awarded the national standard, which sets out a level of good practice for training and development of people to achieve business goals. 1A The Dental Practice, which was established by Allen Branley in 2000, offers NHS and private dental care to over 11,000 registered patients. It is continually growing and recently opened its sixth surgery within the practice. 